\title{
Análisis de la expansión urbana del municipio de Facatativá desde las políticas de ordenamiento territorial en el periodo 2002 2011
}

\author{
Analysis of urban expansion of the municipality of Facatativá \\ from the policies of territorial planning in the period 2002 2011
}

\section{Resumen}

\section{Ana Victoria Rincón Martínez ${ }^{1}$}

La expansión urbana directamente relacionada con la dinámica demográfica se materializa a nivel local por el incremento de áreas urbanizadas. El proceso de transformación y ocupación del espacio se da en forma planificada, en la medida en que se apliquen mecanismos de intervención por parte del Estado. En este artículo se presentan los resultados del trabajo de investigación desarrollado en la zona urbana del municipio de Facatativá, que comprende los años 2002 a 2011, período en el que se pueden identificar patrones de distribución espacial determinados por la implementación del Plan de Ordenamiento Territorial en la expansión urbana. Esta investigación se enmarcó en la geografía urbana y se efectuó con apoyo en estadísticas catastrales y cartografía del plan de ordenamiento del municipio, información que fue complementada con la revisión documental y la aplicación de encuestas semicontroladas y entrevistas a actores involucrados, para identificar la incidencia de las políticas urbanas en el proceso de expansión frente a la dinámica urbana propia del municipio.

Palabras clave: Desarrollo urbano, expansión urbana, planificación urbana, Facatativá. 


\section{Abstract}

Urban expansion, directly related to demographic dynamic, materializes locally by increasing urbanized areas. As a process of transformation and land use, it is given as a planned intervention mechanism which is implemented by the state. This article presents the results of the research work carried out in the urban area of the municipality of Facatativá and temporally between the years 2002-2011, a period in which spatial patterns can be determined by the implementation of the Land Use Plan in urban expansion. Framed in urban geography, this research was conducted with support in statistics and cadastral mapping of the township zoning plan, supplemented by the document review and implementation of semicontrolled surveys to identify the impact of urban policies in the process of expansion from the urban dynamics of the municipality.

Keywords: Urban development, urban expansion, urban planning, Facatativá. 


\section{Introducción}

El crecimiento demográfico como fenómeno generalizado a nivel mundial conlleva el proceso de expansión urbana dada por la concentración de la población y las actividades económicas en las principales ciudades. De esta manera, la expansión urbana está relacionada con la dinámica demográfica y se materializa en la ocupación del espacio, proceso que es posible analizar en dos escalas: a nivel local, por el incremento de áreas urbanizadas al interior y fuera de un núcleo urbano establecido, y a nivel regional, por la existencia de centros urbanos de diferente tamaño y jerarquía, cuya cercanía genera vínculos y relaciones desde el punto de vista funcional.

La expansión urbana puede darse de manera controlada y ordenada, siempre que este proceso de transformación y ocupación del espacio sea orientado mediante acciones de planificación, pues, de otra manera, genera formas de ocupación espontánea y marginal (Solá-Morales, 1997). Las acciones de planificación que refiere este autor como operaciones de parcelación, urbanización y edificación, corresponden a la planificación física en el marco del ordenamiento territorial, definido en Colombia como un mecanismo de intervención que busca orientar el desarrollo territorial y regular la utilización, la transformación y la ocupación del espacio urbano (DNP, 2010).

En el caso particular de Colombia, desde la década del sesenta ya se observaba la tendencia al crecimiento y la expansión urbana de las ciudades principales, tema que convocó la atención de planificadores y tomadores de decisiones, según se concluye de la revisión de las leyes y los planes nacionales de desarrollo efectuada en el curso de la investigación. El Estado colombiano ha establecido mecanismos para la intervención del espacio urbano, teniendo en cuenta tanto el ámbito local como regional; como es el caso del ordenamiento territorial municipal, vigente desde el año 1997 como instrumento de planificación.

Como efecto de la dinámica demográfica se ha acentuado la concentración de la población y las actividades económicas en las principales ciudades del país, principalmente en Bogotá, donde se ha propiciado la expansión urbana más allá de sus límites. De igual manera, a los municipios localizados en inmediaciones de la capital llega población de todas partes del país en busca de bienes, servicios y oportunidades de empleo. Al mismo tiempo y de manera particular, la especialización industrial y los cultivos de flores han hecho que la Sabana de Bogotá sea hoy el escenario de diversos procesos urbanos, donde se produce su transformación de un espacio con vocación tradicionalmente agrícola hacia un carácter cada vez más urbano.

En este conjunto formado por Bogotá como centro principal y los centros urbanos a su alrededor - los cuales, cada vez son más extensos-, se integra el municipio de Facatativá, que está situado en el borde occidental de la Sabana de Bogotá y se vincula mediante la oferta de 
servicios con municipios del departamento de Cundinamarca, y con una posición estratégica, pues hacia este sector se prevé la expansión futura de Bogotá. En estas condiciones, la expansión urbana del municipio debe responder a un proceso planificado e integrado a la dinámica regional.

En este contexto, el trabajo de investigación tuvo como hipótesis demostrar la incidencia de las políticas urbanas en el proceso de expansión urbana, en un contexto marcado por procesos urbanos de carácter regional. Con este propósito, y para el caso particular del municipio de Facatativá, en el estudio se identificaron las políticas urbanas que repercuten en el proceso de expansión urbana y los patrones de distribución espacial determinados por la implementación del Plan de Ordenamiento Territorial.

La investigación elaborada resulta pertinente, por su aporte de análisis desde el conocimiento geográfico, en la previsión y orientación de la expansión urbana en los planes de ordenamiento territorial, aspectos en los que se evidencia insuficiencia teórica y metodológica. Los resultados de esta investigación se expresan en la representación cartográfica y datos de evaluación de la expansión urbana del municipio de Facatativá, de interés para el proceso de revisión del Plan de Ordenamiento Territorial.

\section{Problema de investigación}

En general y según las estadísticas de población, desde la década del cincuen- ta del siglo $\mathrm{XX}$, la tendencia histórica en Colombia muestra un proceso de crecimiento y de concentración de la población en los centros urbanos y con mayor intensidad en ciudades capitales y las zonas urbanas cercanas. Las cifras del Censo General 2005, que se presentan en la Tabla 1 , indican que el $28,7 \%$ de la población total del país se concentra en cuatro ciudades capitales: Bogotá, Medellín, Cali y Barranquilla. Sin embargo, Bogotá aglutina el $56 \%$ de la población urbana del país (DANE, 2006).

Además, en el panorama nacional, Bogotá ha provocado un efecto en las zonas urbanas situadas en sus alrededores, las cuales también muestran un proceso de crecimiento debido a dinámicas particulares que llevan a que la expansión urbana sea un proceso vertiginoso de ocupación del suelo. La reducción de espacio disponible para la expansión de la ciudad, sumada a las limitantes que ocasiona la disposición del relieve y las restricciones ambientales establecidas en los cerros orientales de Bogotá, la ciudad ha dirigido su expansión urbana hacia el territorio de la Sabana de Bogotá, causando distintos procesos urbanos en su área circundante. Según las proyecciones de población del DANE (2006), para el año 2020 habrá una concentración de cerca de 12 millones de habitantes en la Sabana, un $50 \%$ más de la población registrada en el Censo General 2005.

Este reconocimiento de la dinámica de crecimiento urbano que se evidencia en los municipios de la Sabana de Bogotá, hace que el análisis de la expansión ur- 
Tabla 1. Datos de población en las principales ciudades

\begin{tabular}{|c|c|c|c|}
\hline \multirow{2}{*}{ Nombre del municipio } & \multicolumn{3}{|c|}{ Población Conciliada } \\
\cline { 2 - 4 } & Cabecera & Total & $\%$ Urbano \\
\hline Bogotá, D.C. & 6.824 .510 & 6.840 .116 & $99,8 \%$ \\
\hline Medellín & 2.175 .681 & 2.214 .494 & $98,2 \%$ \\
\hline Cali & 2.083 .171 & 2.119 .908 & $98,3 \%$ \\
\hline Barranquilla & 1.142 .312 & 1.146 .359 & $99,6 \%$ \\
\hline $\begin{array}{c}\text { Subtotal ciudades } \\
\text { principales }\end{array}$ & 12.225 .674 & 12.320 .877 & $99,2 \%$ \\
\hline Total país & 31.890 .892 & 42.888 .592 & $74,4 \%$ \\
\hline $\begin{array}{c}\text { Participación ciudades } \\
\text { principales }\end{array}$ & & $28,7 \%$ & $38,3 \%$ \\
\hline
\end{tabular}

Fuente: Censo General, DANE, 2005.

bana y la previsión de espacios hacia el desarrollo futuro tome mayor relevancia en el campo de la planificación, como necesidad para superar la expansión espontánea y desordenada. Como una respuesta a esta necesidad, se encuentra dentro de las políticas de ordenamiento territorial ${ }^{2}$ que la administración municipal debe prever espacios en la categoría de suelos de expansión urbana con proyección temporal a medio y largo plazo.

La delimitación del suelo de expansión hace parte de la ordenación del territorio, cuya esencia es lograr un determinado orden físico para orientar la expansión urbana de forma ordenada y organiza$d a$ (Troitiño, 2006). En este sentido, el ordenamiento territorial municipal, entre otros aspectos, busca controlar la

\footnotetext{
El ordenamiento territorial como instrumento de planificación con aplicación en los municipios, tiene carácter de política pública, tal como lo señala Massiris (2005), y particularmente se orienta a solucionar la necesidad de organizar el uso y ocupación del territorio.
}

ocupación del espacio físico urbano e incorpora instrumentos de gestión del suelo apropiados a las exigencias del desarrollo local; también estrategias y métodos para establecer las normas en cada municipio para la ordenación de las actividades, la infraestructura y los equipamientos necesarios, tal como lo señala Massiris en el análisis de las políticas de ordenamiento territorial en América Latina $(2009$, p. 125). Así, el ordenamiento considera como sujeto el espacio urbano en el que se concentra la población y aquel espacio que se destina para el futuro crecimiento de la ciudad.

A partir de estas consideraciones de la dinámica urbana y de los principios que consagra conceptualmente el ordenamiento territorial, se cuestiona si las políticas urbanas del Plan de Ordenamiento Municipal son coherentes con la dinámica propia del crecimiento del municipio de Facatativá. 


\section{Descripción de la zona de estudio}

El área de estudio de la investigación es la zona urbana del municipio de Facatativá, localizado a los $04^{\circ} 48^{\prime} 45^{\prime \prime}$ de latitud norte y $74^{\circ} 21^{\prime} 21^{\prime \prime}$ de longitud oeste, en el extremo occidental de la Sabana de Bogotá y en el centro del departamento de Cundinamarca, a una altura de 2.600 msnm, con una superficie de $160 \mathrm{~km}^{2}$. Situado a 34 km de Bogotá, el municipio incluye una amplia zona plana de sabana, circundada por una cadena de cerros entre los cuales se destacan el ramal de Barroblanco, Manjuy, el Mirador, Cuchilla Las Pilitas, donde nacen varias corrientes hídricas que cruzan el territorio, entre ellas: los ríos Los Andes y Botello y las quebradas Mancilla y Guapucha. La zona plana está dedicada a la actividad agropecuaria, principalmente a la ganadería y al cultivo de flores; en ella se distingue la cabecera urbana del municipio y centros poblados como Santa Marta, Tierra Grata y Pueblo Viejo, además de pequeños núcleos dispersos.

Facatativá fue fundado en el año 1600 , en el lugar de un importante asentamiento indígena de su mismo nombre. Desde su fundación, su desarrollo ha estado ligado a la ubicación geográfica al borde de la Sabana de Bogotá, la distancia a la ciudad de Bogotá, la configuración física de su territorio en cuanto a la disposición del relieve y la disponibilidad de fuentes hídricas para el sustento de la pobla-

Figura 1. Mapa de localización del municipio de Facatativá

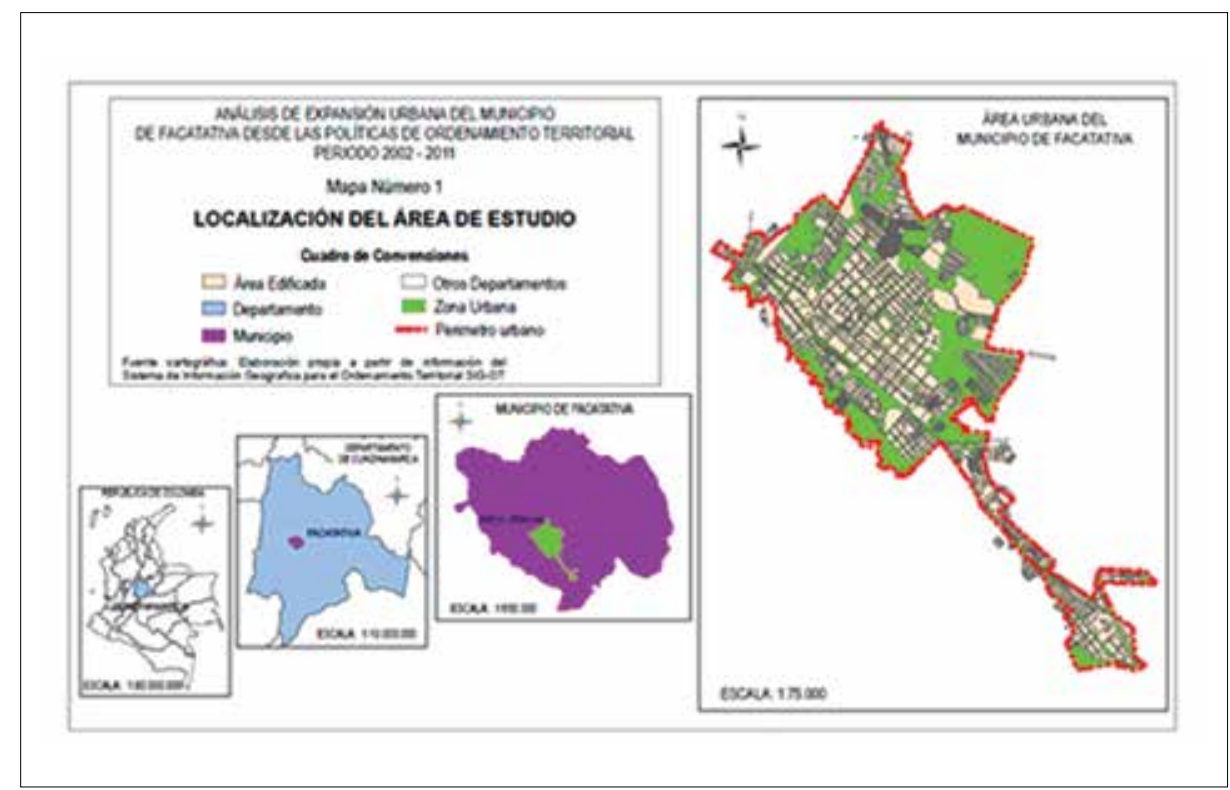

Fuente: SIGOT- IGAC (2012) 
ción. Además, el emplazamiento como cruce de varios caminos: en la época de la Colonia, caminos de herradura que conectaban a Santafé de Bogotá y el río Magdalena con las poblaciones de Honda y Girardot; luego, en la segunda mitad del siglo diecinueve, el ferrocarril, y actualmente, la red de carreteras que conecta el centro y el norte del país, hacia Caldas, Antioquia y la región Caribe (Alcaldía Cívica de Facatativá, 2011).

La zona urbana se localiza en suelos de origen fluviolacustre, profundos a moderadamente profundos y derivados de cenizas volcánicas, en pendientes menores al 7\% (IGAC, 1984). Estos suelos son clasificados según su capacidad de uso en las categorías agrológica II y III (IGAC, 2012b). En el resto del territo- rio se distinguen dos grandes unidades diferenciadas por la pendiente, suelos de montaña en el rango de $12-50 \%$ al oriente en las estribaciones del cerro de Manjuí y los otros cerros que lo circundan. Una unidad de menor extensión en el sector de Manablanca y Santa Marta, de suelos aluviales, superficiales y mal drenados, en pendiente menor al $3 \%$.

Facatativá tiene una población total de 107.452 habitantes de acuerdo con el Censo General 2005 (DANE, 2006). En el período 1993-2005 su población aumentó en 41.155 habitantes, a razón de 3.429 habitantes por año (Figura 2).

$\mathrm{El}$ incremento, equivalente al $38,3 \%$, es superior al promedio nacional de $22,8 \%$ para el mismo período. El municipio

Figura 2. Crecimiento de la población de Facatativá.

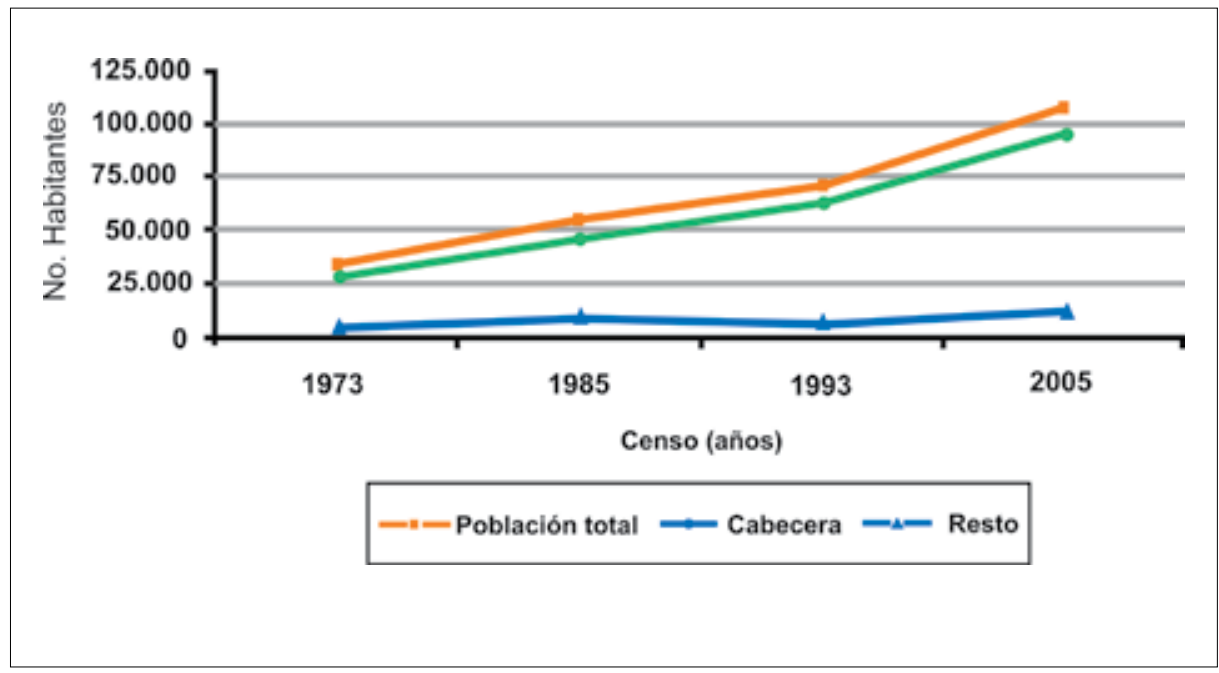

Fuente: Elaboración propia a partir de DANE (2006) 
se caracteriza también por el grado de urbanización, dado que el $89 \%$ de la población total se concentra en la zona urbana, y por el grado de densidad de la población urbana, calculado en 195 habitantes por hectárea.

El área urbanizada muestra una disposición en forma de cuadrícula en el centro de la ciudad e irregular hacia la periferia. La vía nacional que comunica a Bogotá con Medellín y la costa Atlántica la atraviesa, favoreciendo la disposición lineal en los extremos de la ciudad. El uso del suelo urbano es predominante residencial, con una intensa actividad comercial e institucional en el centro. Según datos del censo 2005, el 57,7\% de los establecimientos se dedica a la actividad comercial y el 33,4 a la prestación de servicios, tan solo el $8,2 \%$ corresponde a establecimientos industriales, lo que indica el escaso desarrollo de esta actividad (DANE, 2006).

Por otra parte, en razón a su centralidad administrativa, Facatativá es capital de la provincia Sabana Occidente del departamento de Cundinamarca, y, de acuerdo con la organización urbanoregional, la ciudad se clasifica como centro de relevo principal. Dentro del departamento de Cundinamarca, Facatativá tiene igual jerarquía que Fusagasugá, Zipaquirá y Girardot. $\mathrm{La}$ influencia regional, medida por la cantidad de servicios institucionales que el municipio ofrece, alcanza a 48 municipios del departamento, estos servicios son prestados por entidades de gobierno del nivel nacional y regional situadas en el municipio (Alcaldía
Cívica de Facatativá, 2002b). Además de la oferta de servicios institucionales y comerciales, cumple la función de ciudad dormitorio, pues buena parte de los habitantes depende para sus actividades de la ciudad de Bogotá, que genera un movimiento pendular diario hacia Bogotá, calculado en 21.157 habitantes (Muñoz, 2007).

\section{Metodología}

Según su objetivo, la investigación se desarrolló con aplicación de métodos distintos de tipo cualitativo y cuantitativo, la revisión documental y entrevistas a actores locales, así como el examen de los fundamentos conceptuales y normativos de las políticas urbanas, los cuales se complementaron con el análisis cartográfico y estadístico, en el orden que se muestra en la Figura 3.

Los resultados que se presentan en este artículo corresponden al desarrollo de la revisión documental y cuantitativa de los objetivos 1 y 2 de la investigación.

\section{Resultados y discusión}

\subsection{Respecto a las políticas urbanas}

El crecimiento urbano de Facatativá, analizado como proceso histórico, muestra tendencia a la densificación del espacio urbano. La delimitación de suelos de expansión urbana y su desarrollo responde a un proceso controlado en el 
Figura 3. Síntesis del marco metodológico de la investigación

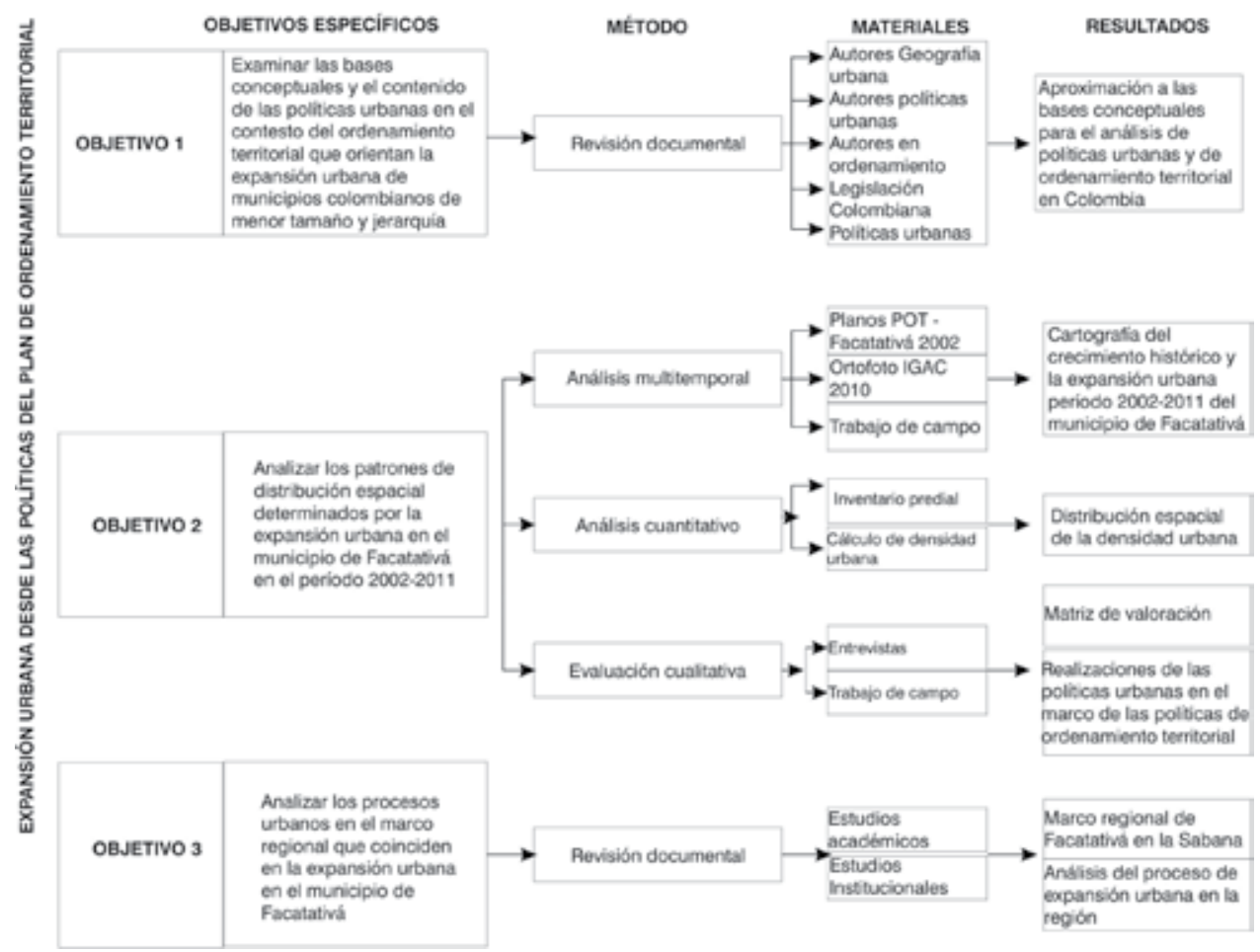

Fuente: Elaboración propia

que el incremento de suelo destinado a la urbanización, limitado por las restricciones de ocupación de suelos de alto valor para el uso agropecuario, ha generado una tendencia a la densificación cada vez mayor. En este sentido se encuentra relación con las políticas que orientan el desarrollo urbano desde el Gobierno nacional.

Al revisar las leyes y los planes nacionales de desarrollo, se concluye que en estos no se encuentra una política específica para reglamentar la expansión urbana. Contrario a una ciudad extendida, la política urbana en Colombia busca una ciudad densificada o ciudad compacta (DNP, 2004). En el mismo sentido, en las políticas se establecen mecanismos que favorecen o limitan este proceso urbano

La Ley Orgánica de Desarrollo Urbano definió como espacio por intervenir, las áreas de reserva para futuras extensiones de la ciudad (Ley 61 de 1978, artículo 11). Para la regulación de estas áreas, se declaró su carácter de utilidad pública o interés social, y así fue reiterado en el 
Decreto ley 1333 de 1986 (artículo 43). Esta declaratoria conllevó la potestad de la administración de decretar la expropiación de predios urbanos, como un instrumento para favorecer el desarrollo de la expansión urbana. Sin embargo, el uso de este instrumento no se evidencia en el proceso de expansión del municipio de Facatativá.

Algunas limitaciones y restricciones se establecieron desde el año 1986: los municipios, particularmente aquellos con más de 300.000 habitantes o aquellos que sin atender a su tamaño estuvieran localizados en un radio de $60 \mathrm{~km}$ del centro urbano mayor, debían delimitar las denominadas zonas de reserva agrícola alrededor y en forma contigua a la zona urbana para producción agrícola pecuaria y forestal. Los procesos de urbanización en el suelo agrícola de clase I, II y III ya estaban restringidos entonces, no obstante estaba abierta la posibilidad de utilizarlos cuando no había otra calidad de suelos (artículos 53 y 54, Código de Régimen Municipal)

Se destaca que en esa época la reglamentación no definía las zonas de transición urbana que hoy se conocen como suelo suburbano y de expansión urbana; se diferenciaba solamente suelo urbano y suelo rural, y la transición estaba dada por una mayor producción agrícola, un modelo de lugar central en el que la distancia a la zona de producción agrícola se relacionaba con el consumo. En otro aspecto, se estableció la zona de reserva agrícola. En ella el municipio definía los usos del suelo como norma de cumplimiento obligatorio e inmodificable, y cualquier cambio involucraba la acción policiva y sancionable pecuniaria y penalmente (artículo 60, Código de Régimen Municipal). Esta norma tuvo vigencia hasta la promulgación de la Ley 9 de 1989.

La definición precisa de áreas para desarrollar en el futuro, se formuló en la Ley 388 de 1997, con la incorporación de categorías de suelo de expansión urbana y suelo suburbano, como zonas de transición para la expansión urbana planificada.

Posteriormente, en el artículo 4 del Decreto 3600 de 2007, se establecieron normas relativas a los determinantes de ordenamiento del suelo rural y al desarrollo de actuaciones urbanísticas de parcelación y edificación en este tipo de suelo. El decreto establece que en los terrenos destinados a producción agrícola y ganadera y explotación de recursos naturales no se pueden hacer actuaciones urbanísticas de subdivisión, parcelación, o edificación que impliquen alteración o transformación del uso actual. Se refiere a suelos aptos para la explotación agropecuaria y a aquellos suelos requeridos para protección forestal de fuentes de aguas.

Particularmente en la Sabana de Bogotá, en la que predominan suelos de categoría II y III, frente a la dinámica de crecimiento demográfico y la concentración de actividades, esta restricción orienta las políticas hacia la densificación antes que a la expansión de las zonas urbanas. Sin embargo, el modelo de producción agrícola que especializaba a la sabana 
inevitablemente se ha trasformado hacia procesos de urbanización.

En este sentido, se encuentra que la Ley 1469 de 2011 abre la posibilidad de reconsiderar esta limitación para el desarrollo de los macroproyectos de interés social nacional, dando la posibilidad de establecer una reglamentación especial para proceder al desarrollo sobre estos tipos de suelo (artículo 21). Dado lo reciente de su promulgación, los resultados de la aplicación aún no se pueden medir.

\subsection{Respecto a la expansión urbana del municipio de Facatativá}

Facatativá muestra una tendencia mayor al uso residencial y a la concentración de la vivienda de estrato socioeconómico 2 , característica de la vivienda de interés social y vivienda prioritaria que predomina en el desarrollo urbano reciente. Como efecto, el tamaño de los predios también tiende a ser cada vez menor y la densidad urbana aumenta. De esta manera, la expansión de la ciudad se ha dado sobre los espacios libres disponibles al interior del perímetro urbano y sobre superficies limitadas localizadas en la periferia.

En su evolución histórica, Facatativá se muestra como una ciudad compacta que mantuvo su morfología hasta el inicio de los procesos de urbanización en serie ocurridos en la década del ochenta; desde entonces exhibe patrones dispersos y discontinuos hacia la periferia de la ciudad, relacionados con la disponibilidad de predios de gran extensión para el desarrollo de este tipo de urbanización.
De manera reciente, los espacios libres han sido desarrollados y la tendencia ha sido a densificar el espacio construido. Durante un tiempo, la actividad edificadora estuvo detenida en el municipio, en razón a la restricción que imponía la Ley 388 de 1997 en la expedición de licencias de construcción para que los municipios elaboraran su plan de ordenamiento dentro de los plazos establecidos (entrevista a Martínez, J. E., 2009). En el caso de Facatativá, esta interrupción se produjo en un lapso de cinco años desde la promulgación de la ley y hasta que el plan de ordenamiento territorial fue aprobado en el año 2002 por decreto emitido por el alcalde.

Por esta razón, la edificación se reactivó a partir del 2002, con prioridad en el desarrollo de las áreas disponibles al interior del perímetro urbano vigente, y luego en el suelo de expansión urbana (Alcaldía Cívica de Facatativá, 2002a, art. 76). En forma efectiva, en el año 2005 se inició la implementación tanto de planes parciales privados y de aquellos declarados como oficiales en el mismo acuerdo de aprobación del plan. Esto indica que la expansión urbana en Facatativá ha sido un proceso desarrollado en los últimos cinco años, caracterizado por la participación de actores privados y la administración municipal.

A partir del mapa de crecimiento histórico de la ciudad que se ilustra en la figura 4 se observa que el área urbanizada en el período 2002-2011 bordea el área construida preexistente en el año 2002; de esta manera el plano de la ciudad adquiere 
Figura 4. Mapa de crecimiento histórico de Facatativá.

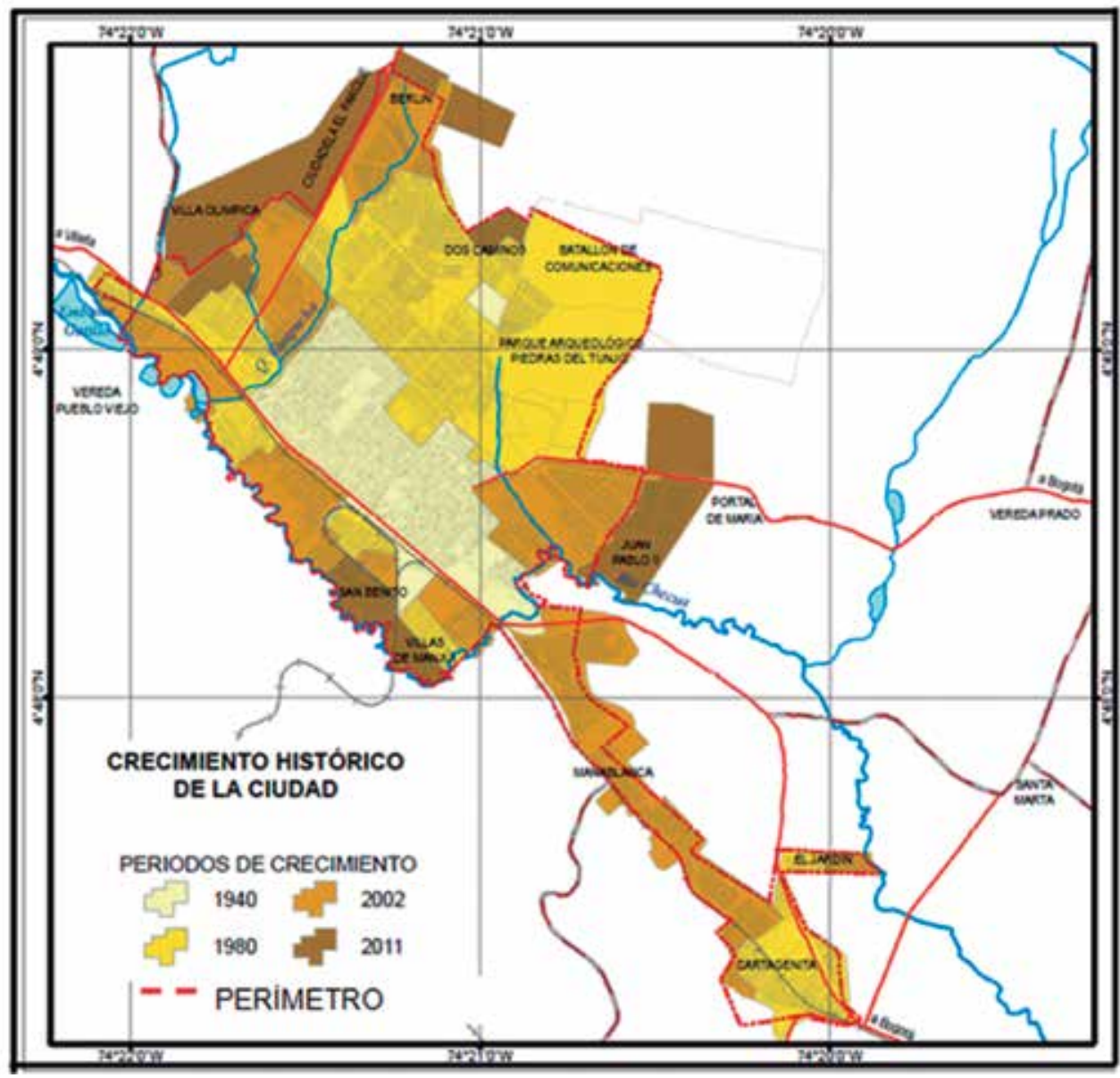

Fuente: Elaboración propia a partir de cartografía POT. Alcaldía de Facatativá (2002 a $)$.

Fotografías aéreas IGAC.

una forma rectangular que se extiende por la vía Troncal de Occidente en los extremos norte y sur de la zona urbana. Se observa también el desarrollo reciente de proyectos de urbanización al interior y en el área contigua del perímetro urbano, acorde con las áreas previstas en la categoría de suelos de expansión urbana. (Figura 5).
En cuanto al análisis según estrato socioeconómico $^{3}$, comparando los años 2002 y 2011, antes de la incorporación de los nuevos barrios, Facatativá ya mostraba predominancia de uso residencial con es-

3 El estrato socioeconómico se asumió como una variable nominal que indica las condiciones de la vivienda, su entorno y las condiciones socioeconómicas de la población. 
Figura 5. Mapa de suelo de expansión urbana.

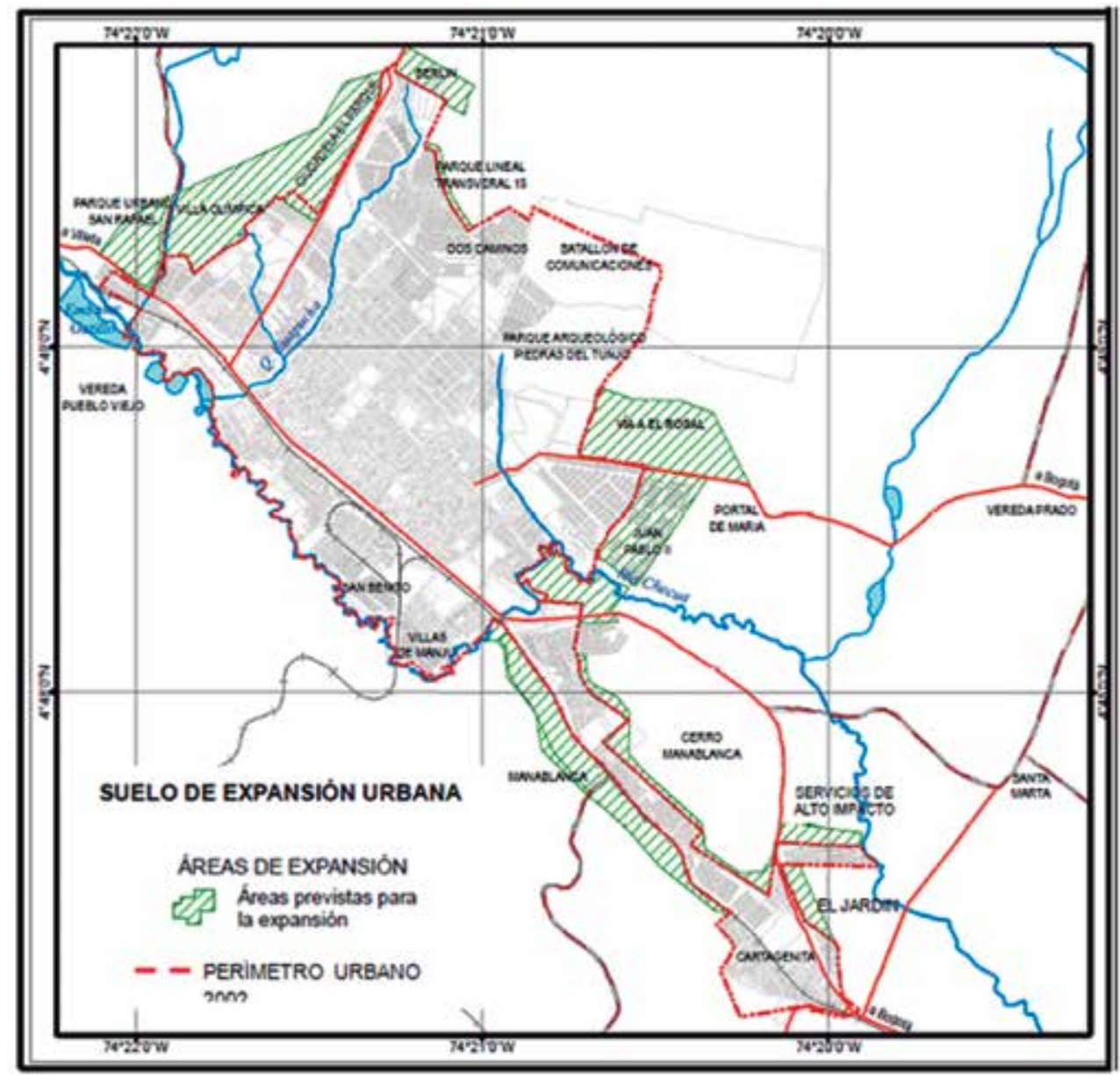

Fuente: Elaboración propia a partir de cartografía POT. Alcaldía de Facatativá (2002 a $)$.

tratos del 1 al 4 . Inicialmente en el municipio se desarrolló una alta concentración de vivienda en estrato 2 , pues el $40 \%$ de predios existentes en el 2002, situados en este estrato, muestra un incremento del $49 \%$ debido a la incorporación de alrededor de 3.500 viviendas (Alcaldía Cívica de Facatativá, 2012), frente a un comportamiento relativamente estable de los demás estratos, sin culminar aún el desarrollo de los proyectos previstos para la expansión urbana. Esta concentración indica el tipo característico de la vivienda de interés social, principal objetivo del plan de ordenamiento territorial y de la intervención oficial. (Figura 6).

De otra parte, las estadísticas catastrales municipales ofrecen una distribución de frecuencias de predios urbanos por 
Figura 6. Distribución de estratos socioeconómicos en el municipio.

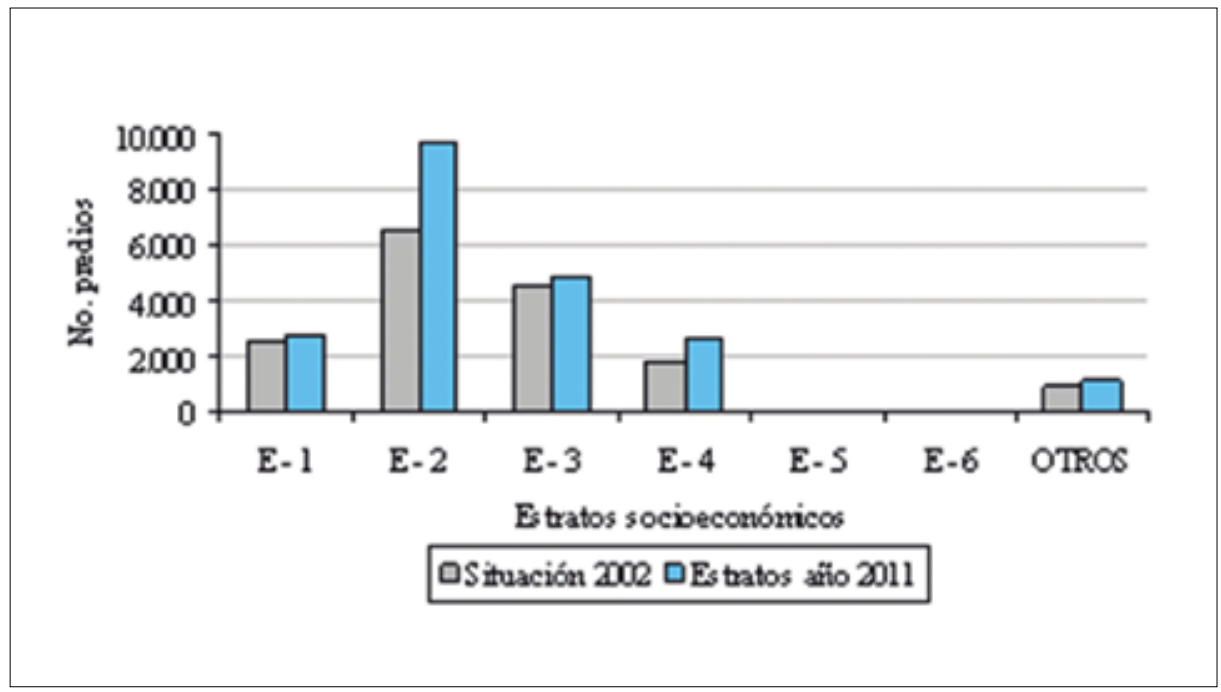

Fuente: Elaboración propia a partir del mapa de estratos y barrios. Alcaldía de Facatativá (2012)

rangos. A partir de esta información se cuantificó la evolución en cuanto a la densidad urbana. El área urbana en la base de datos catastral es de 575,2 hectáreas en el año 2011. (Figura 7).

La idea del territorio cada vez más fraccionado por el tamaño de la propiedad se evidencia en el aumento del número de predios: en el año 1993, Facatativá registraba 12.290 predios urbanos; en el 2005 se incrementó en cerca del $50 \%$ (18.738 predios) a un ritmo de crecimiento de 537 predios/año. Este ritmo, que aumentó en el último período a 747 predios/año, correspondiente con el mayor desarrollo en la expansión urbana, ya en el 2011 alcanzó 23.200 predios urbanos, doblando prácticamente su registro del año 1993. Por otro lado, la propiedad tiende a ser cada vez más pequeña, otro indicador de la mayor densidad urbana. Lo que se observa en la tabla de frecuencias acumuladas, es la concentración de predios de tamaño menor a $200 \mathrm{~m} 2$, de manera constante en el tiempo, equivalente al $72 \%$ del total. (Figura 8).

Se destaca que el número de predios con extensión menor de $100 \mathrm{~m} 2$ es cada vez mayor, al igual que los predios en propiedad horizontal (PH). Así mismo se observa constante el número de predios de mayor extensión, particularmente los predios con extensión mayor a una hectárea, extensión mínima para desarrollo de proyectos de vivienda. La tendencia que muestra es que los predios son cada vez de menor tamaño: el promedio de $72 \mathrm{~m} 2$, que equivale a un lote típico de 6 
Figura 7. Área urbana catastral en hectáreas.

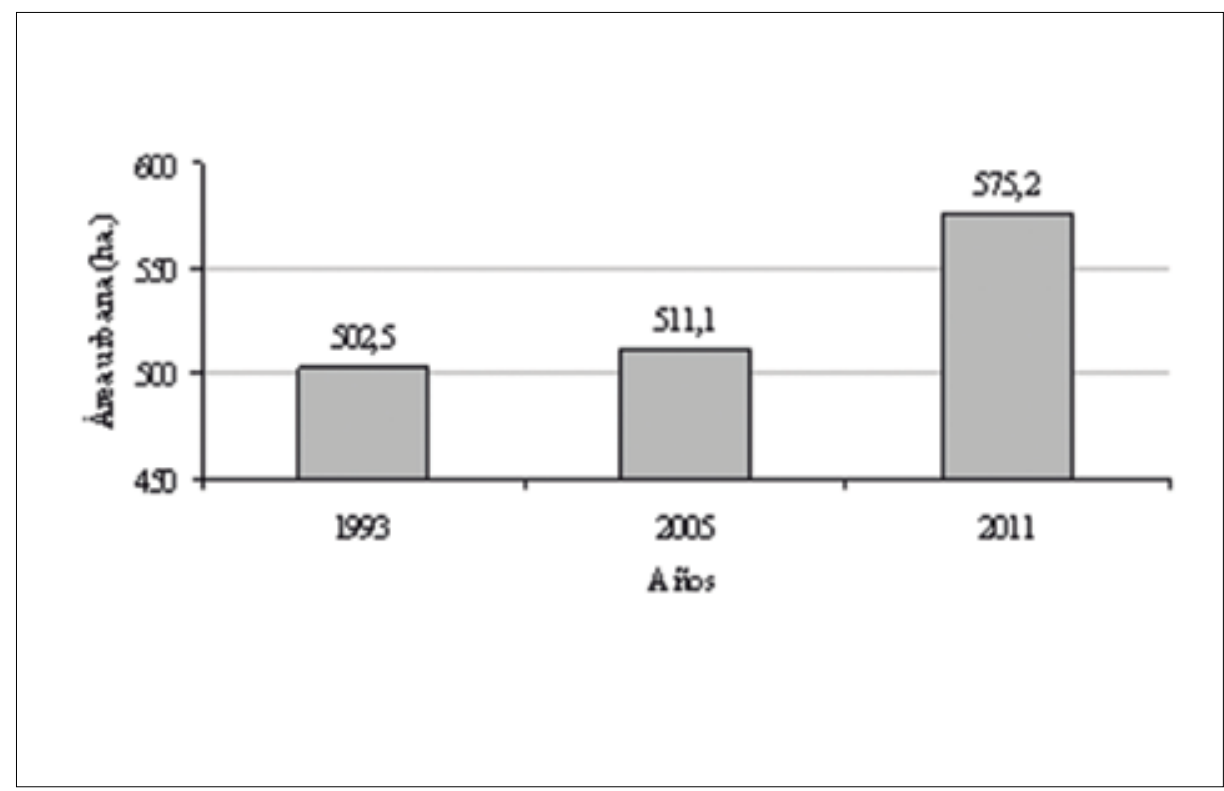

Fuente: Elaboración propia a partir de IGAC $\left(2012^{a}\right)$.

Figura 8. Distribución de predios por rangos de área 1993, 2005, 2011.

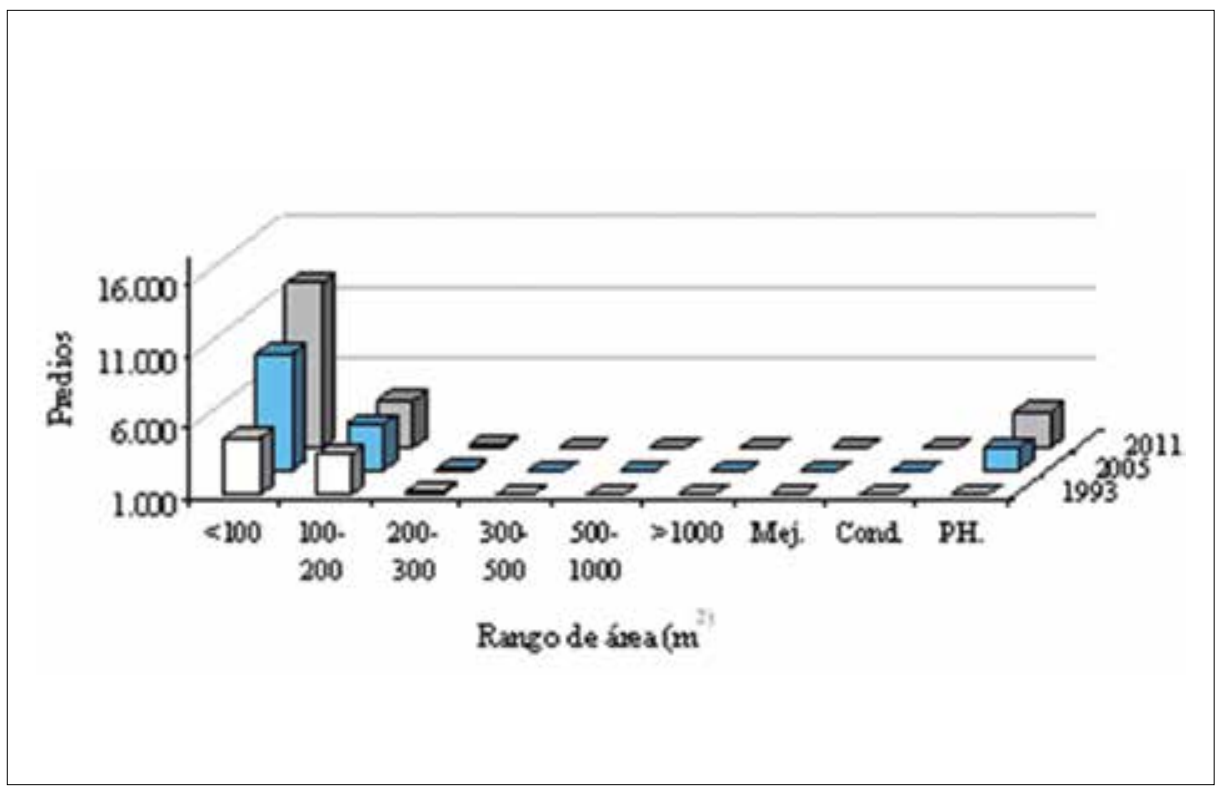

Fuente: Elaboración propia a partir de $\operatorname{IGAC}\left(2012^{\mathrm{a}}\right)$. 
por 12 metros en urbanización, pasó a 64 $\mathrm{m} 2$, una reducción de 8 metros; mientras que los demás rangos tienen aumentos no significativos en proporción al total del lote (4 metros en lotes de 200 a 1.000 $\mathrm{m}^{2}$ ). La observación detallada de los predios del primer rango, menor a 100 $\mathrm{m} 2$, permite reafirmar que la fragmentación de la propiedad es cada vez más alta. (Figura 9).

Además, como se muestra en la figura 10 , se registran cada vez más predios con superficie menor a $50 \mathrm{~m}^{2}$, lo que tiene que ver con las especificaciones estandarizadas para la vivienda de interés social y vivienda prioritaria. En este sentido, la vivienda de interés social y prioritaria sobre la que se basa el desarrollo reciente del municipio, responde a las especificaciones mínimas dadas como una política nacional, las cuales aplican en forma generalizada por los constructores y explica la reducción del tamaño promedio de los lotes y por ende de las edificaciones.

En síntesis, en Facatativá se evidencia una relación entre el crecimiento histórico y la distribución espacial de la densidad, así, el centro histórico presenta una miscelánea de densidad, y, en la medida en que se ha dado el desarrollo reciente, la tendencia ha sido reducir el tamaño de los lotes en las áreas de expansión urbana. Tanto al interior del perímetro urbano como en la categoría de suelos de expansión, el tamaño promedio es menor de 50 $\mathrm{m}^{2}$. También se ha dado una relación de distancia, pues los barrios más alejados o periféricos muestran altas densidades, con excepción de aquellos predios de uso institucional como colegios, parques y los

Figura 9. Reducción en el tamaño de los predios.

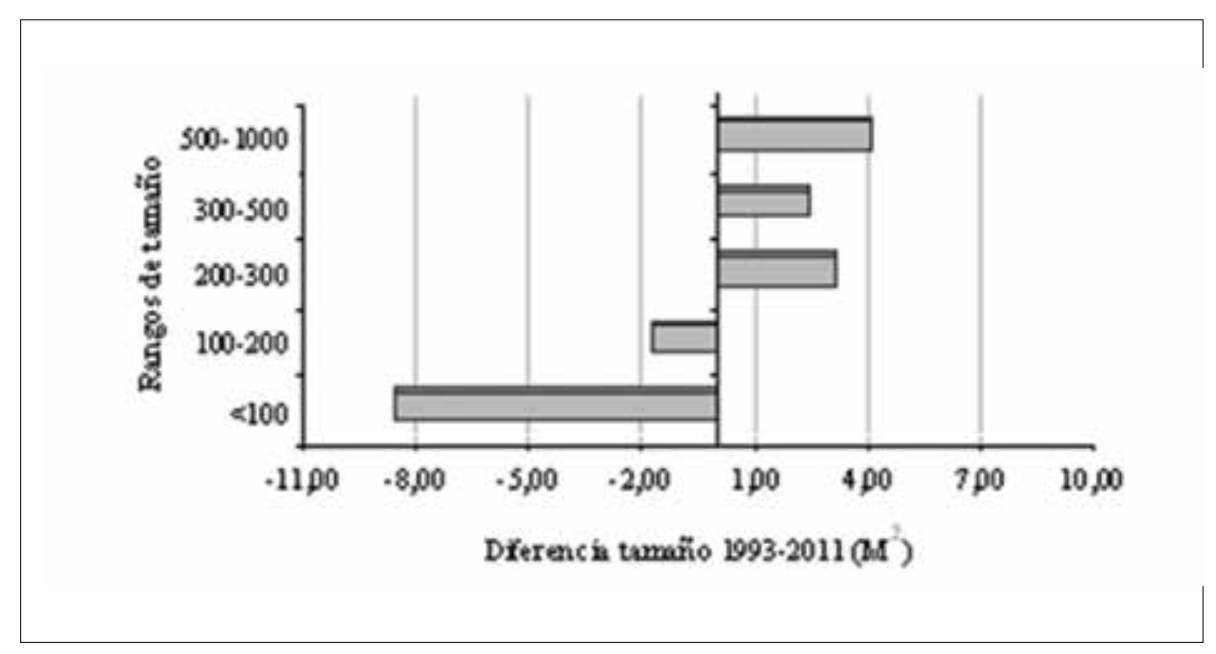

Fuente: Elaboración propia. 
Figura 10. Tendencia del tamaño de predios 2002-2011.

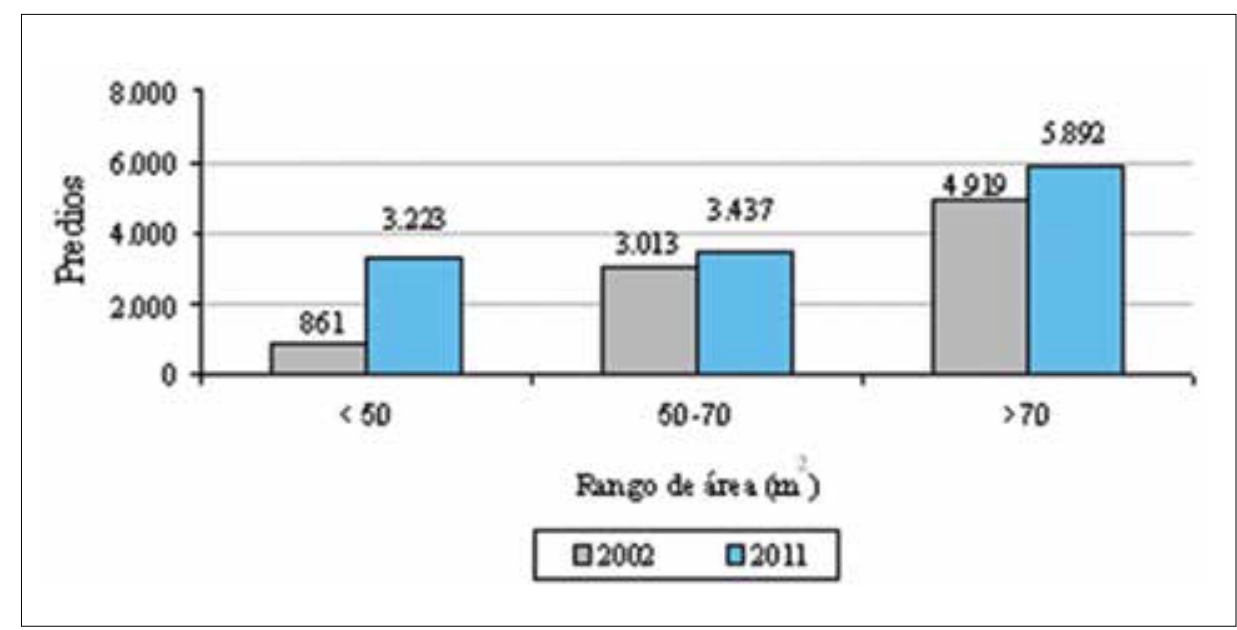

Fuente: Elaboración propia a partir de IGAC (2012 $\left.{ }^{\mathrm{a}}\right)$.

lotes que aún no se ha desarrollado. El desarrollo reciente, según se muestra en el mapa de densidad predial (Figura 11), situado en la periferia de la zona urbana describe un patrón altamente densificado.

\section{Conclusiones}

En el análisis de la expansión urbana, entendida como el incremento de la extensión física causada por los procesos urbanos, según lo señala Carter (1984), el espacio geográfico se concibió en el marco de la geografía urbana como el resultado de los procesos de urbanización, crecimiento y estructuración interna (Ortega, 2000, p. 404). Al incorporar el análisis de la expansión urbana en el marco de las políticas de ordenamiento territorial, el concepto aplicable fue ampliado hacia el enfoque de la geografía política, ya que este considera el espacio como producto de las acciones de regulación o planificación por parte del Estado. Estas acciones se corresponden con el concepto de política obtenido desde las ciencias políticas y definido como el conjunto de decisiones, programas y proyectos de gobierno que de manera práctica llevan implícito el principio de autoridad y poder político que ejerce el Estado sobre el territorio o la sociedad (Thoenig, 2006, p. 334), y se justifican en la atención de necesidades de tipo social y con la participación de actores involucrados, por lo que son definidas como políticas públicas. Se constituye así un espacio de relaciones de poder, por la existencia de intereses y conflictos que deben ser resueltos por las partes. De esta manera, las políticas desde la geografía se entienden como mecanismos de transformación del espacio, y su interés se centra en las transformaciones del espacio causadas por la implementación de las políticas (López y Benito del Pozo, 1999, p. 254). 
Figura 11. Mapa de densidad predial.

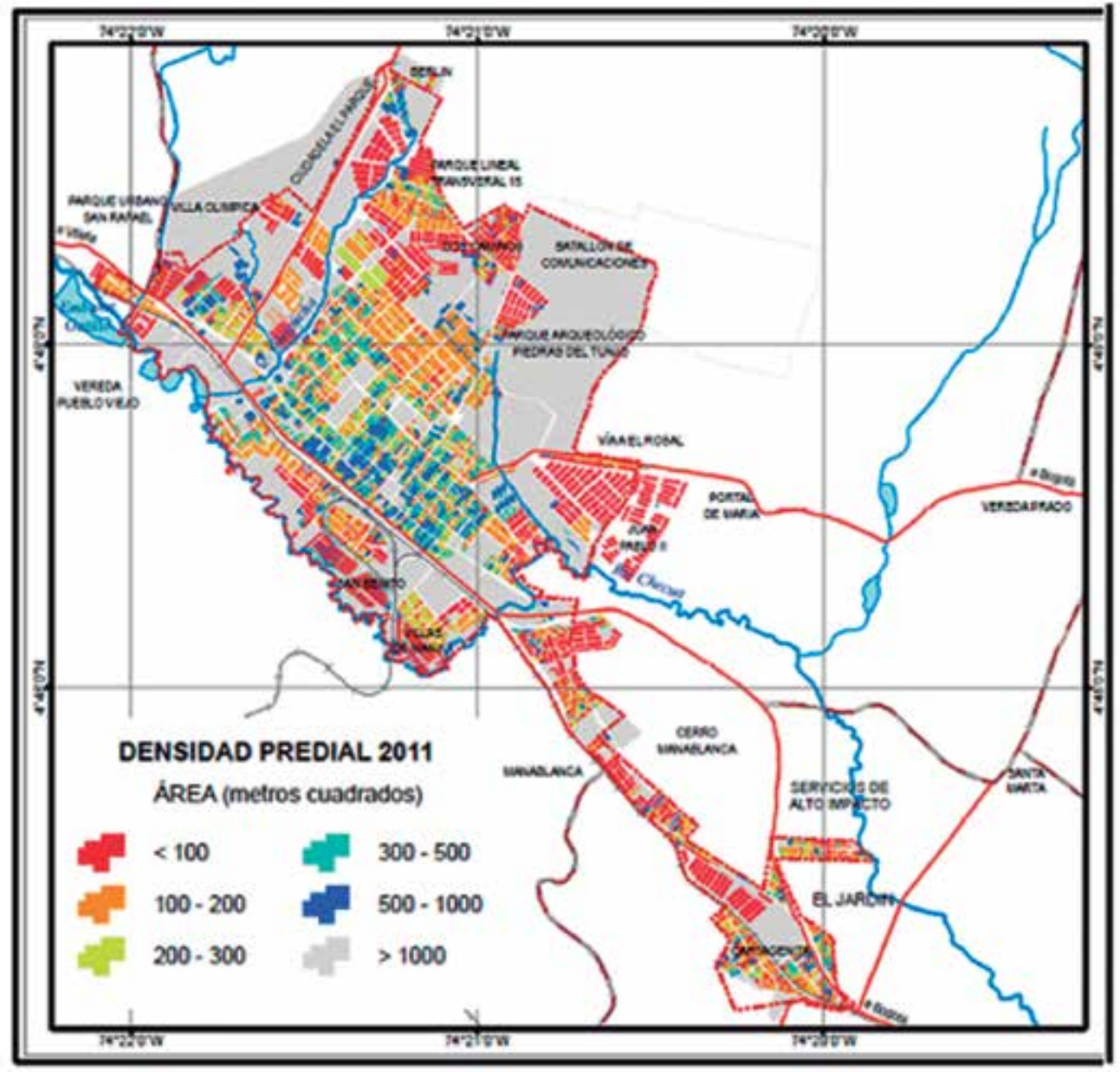

Fuente: Elaboración propia a partir Alcaldía de Facatativá (2002ª).

El acercamiento a este enfoque guió la aplicación en la investigación de dos metodologías propias de estas disciplinas de la geografía: de una parte, el análisis histórico del crecimiento urbano en el que las formas urbanas observadas se asocian a hechos o condiciones históricas propias del lugar (Carter 1984). Por otra parte, la aplicación de estrategias cualitativas, alternativa metodológica que plantea Muller (2002) para el análisis de las políticas públicas, en este caso dirigida a analizar el efecto de la política urbana y los resultados en la transformación del espacio.

Luego de este complemento al marco teórico y metodológico para la investigación, la revisión de la legislación 
y los planes nacionales de desarrollo, aportó a la identificación de las políticas colombianas, particularmente aquellas relacionadas con la expansión urbana.

Al respecto, se identificó que en Colombia el crecimiento de las ciudades ha sido un tema central en la legislación y los planes nacionales de desarrollo. Este proceso, calificado como acelerado y desordenado, ha llevado a abordar de manera recurrente problemas urbanos de distribución de la población, del crecimiento físico de las zonas urbanas y del déficit de vivienda. Todo ello con el fin de establecer políticas y fortalecer los procesos de planeación en todos los niveles de gobierno, particularmente en el nivel municipal.

En este sentido, la política urbana en Colombia se ha construido en dos niveles del espacio urbano, uno es el nivel interurbano, fundamentado en la organización jerárquica y funcional de las ciudades. Sobre este se ha propuesto la creación de redes, sistemas de ciudades o sistemas urbanos, a fin de orientar la distribución de la población, reducir su concentración en ciudades principales y propiciar el desarrollo de ciudades intermedias.

En el nivel intraurbano se orientan acciones que deben ser implementadas por las administraciones municipales en el marco del ordenamiento territorial, para dos aspectos: el desarrollo urbano y la construcción de vivienda. En el primer aspecto, según el objetivo de la política de desarrollo urbano, es deseable un modelo de ciudad densificada, para apro- vechar la infraestructura instalada (DNP, 2004) y contribuir a mejorar las condiciones de vida medidas por el índice de necesidades básicas insatisfechas (NBI). Esta orientación hacia la densificación antes que a la expansión urbana, es una tendencia que ha caracterizado históricamente la política urbana con mayor énfasis en los países en desarrollo más que en los desarrollados (Burgess, 2000, citado por Shlomo et al., 2010).

Por su parte, la política urbana dirigida a la construcción de vivienda de interés social, tiene como propósito dar solución al déficit de vivienda. En este sentido, establece la construcción de vivienda y la infraestructura de servicios, vías, trasporte y espacios públicos y equipamientos como las intervenciones en el espacio. La política orienta así la creación de la estructura urbana en las dimensiones de los macroproyectos de vivienda, con lo que incide en la expansión urbana, de manera un tanto contradictoria con el modelo de ciudad densificada.

$\mathrm{Al}$ respecto se pudo observar que el desarrollo urbano reciente del municipio de Facatativá muestra la consolidación del espacio urbanizable con escasos espacios vacantes y la densificación del área construida particularmente por la edificación de la vivienda de interés social, resultado de las políticas definidas en el plan de ordenamiento territorial que efectivamente están orientadas por las políticas nacionales urbanas del nivel nacional.

También se pudo observar que el proceso de expansión urbana en el municipio de Facatativá, luego de la promulgación del 
plan de ordenamiento territorial, fue un proceso lento en su inicio, pero acelerado a partir del año 2007, especialmente sobre el suelo de expansión urbana. Hasta el 2011 se incorporaron 100,4 hectáreas de área urbanizada, 19 barrios, 5.768 viviendas, y de estas, 4.208 en suelo de expansión urbana y $1.560 \mathrm{al}$ interior del perímetro urbano. De esta manera, el espacio urbanizable se ha consolidado, lo que se evidencia en escasos espacios vacantes y la densificación del área construida.

Este proceso ha sido favorecido particularmente por la edificación de la vivienda de interés social, con una notoria ampliación en el uso residencial hacia los bordes del área urbanizada, al tiempo que la expansión del uso comercial desde el centro histórico y las principales vías. En el análisis del proceso que se dio en Facatativá, se incorporaron tres elementos que indican la transformación de la zona urbana hacia un espacio cada vez más densificado: la clasificación en estratos socioeconómicos, la ampliación del área urbana, y la densidad predial como medida de la densidad urbana. La medida de estos parámetros indica que Facatativá es una ciudad cada vez más densificada, pues mediante las políticas urbanas se ha controlado la adición de superficie a la zona urbana, manteniendo el perímetro urbano estable en períodos largos; también la concentración de población muestra un alto grado de urbanización (del $89 \%$ ), y, por lo tanto, la densidad de población igualmente aumenta.

La medida de una mayor densidad predial deriva que la densidad de población también es mayor, lo cual se ratifica con los datos censales y las áreas de base catastral. Para el 2011 se calcula en 195 habitantes por hectárea, parámetro que sitúa a Facatativá en segundo lugar entre los municipios de Cundinamarca más densamente poblados en su zona urbana, después de Soacha (IGAC, 2009).

Así mismo, la densificación es generalizada, encontrándose su intensificación en todos los estratos socioeconómicos y en diferentes lugares de la zona urbana. En los sectores desarrollados recientemente, el tipo de vivienda se concentra en estrato socioeconómico dos, y el resto, en el estrato cuatro. La densidad predial en ambos casos es igual, puesto que la vivienda se ha edificado sobre lotes cuya dimensión es menor que $50 \mathrm{~m} 2$.

Así, el establecimiento de las políticas del ordenamiento territorial municipal, estimuló en Facatativá el desarrollo de la edificación, con una tendencia ascendente que se prevé será acelerada después del año 2011, debido a que se encontraban en desarrollo varios proyectos que ya incluía el Plan de Ordenamiento Territorial desde el año 2002.

Sin embargo, el auge en la edificación de vivienda no se contrarresta con el desarrollo en otros niveles, puesto que esta solución no ha venido acompañada de la adecuación de espacios de uso público o la mejora de infraestructura instalada para educación y salud. Tampoco ha sido acompañada de la generación de empleo formal, distinto al empleo generado por los cultivos de flores, cuya oferta no resulta suficiente y la estabilidad depende 
de los ciclos del mercado del producto; la alternativa está en el empleo que de manera formal o informal es generado por el comercio como actividad que se destaca por su crecimiento.

En síntesis, se observó que el área urbana del municipio ha llegado a un límite de densificación en el que la alternativa es abrir espacios para la expansión. Sin embargo, la movilidad, entendida como la posibilidad de elegir entre varias opciones de localización potencial de la expansión urbana, se enfrenta a varias restricciones originadas en las condiciones físicas del medio natural.

En este sentido, al deber de proteger los suelos de la Sabana de Bogotá, por su calidad para la explotación agropecuaria (Decreto 3600 de 2007), se suma el establecimiento de la zona de protección de los cerros que circundan la zona urbana, circunscritos en el Distrito de Manejo Integrado Manjuí-Salto del Tequendama, establecido por la Corporación Autónoma Regional de Cundinamarca -CAR(Acuerdo 43 de 1999). Al mismo tiempo, la imperiosa necesidad de mantener bajo condiciones adecuadas de manejo y administración el nacimiento de numerosas fuentes de agua y los depósitos en acuíferos - con los que el municipio mantiene autonomía en el suministro de agua potable, a diferencia de otros municipios situados hacia el centro de la Sabana de Bogotá-, son elementos que han determinado las limitaciones para la ampliación del suelo urbano en el municipio de Facatativá.

La expansión urbana ha sido controlada y planificada hasta el año 2011, pero se acerca ya a su límite y exige considerar la ampliación de la zona urbana. De otra manera, frente al crecimiento de la población, Facatativá se encuentra abocado a un proceso de crecimiento marginal y espontáneo, del cual ya hay indicios en los centros poblados situados en la zona rural. 


\section{Literatura citada}

Alcaldía Cívica de Facatativá. (2002 a). Acuerdo 69 de 2002, adopción del plan de ordenamiento territorial 2001-2021.

Alcaldía Cívica de Facatativá. (2002b). Plan de ordenamiento territorial Facatativá 20012021. Documento técnico de soporte. Oficina Asesora de Planeación. Recuperado de http://www.car.gov.co/?idcategoria $=3459$

Alcaldía Cívica de Facatativá. (2011). Sitio oficial del municipio Facatativá. Información general. Recuperado de http:// Facatativá-cundinamarca.gov.co

Alcaldía Cívica de Facatativá. (2012). Mapa de estratos socioeconómicos. [Archivo en formato digital]. Oficina de Planeación municipal de Facatativá.

Carter, H. (1984). El estudio de la geografía urbana. Edición española. J. Hernández (Trad.). Madrid: Instituto de Estudios de Administración Local. 578 p.

Colombia. Congreso de la República. (2011, 30 de junio). Ley 1469. Medidas para promover la oferta de suelo urbanizable y otras disposiciones para promover el acceso a la vivienda. Diario Oficial, CXLVII, (48116), 104.

Colombia. Congreso de la República. (1997, 24 de julio). Ley 388. Ley de Ordenamiento Territorial. Diario Oficial, CXXXIII, (43091), 4.

Colombia. Congreso de la República. (1989, 11 de enero). Ley 9. Ley de Reforma Urbana. Diario oficial, CXXV, (38650), 1.

Colombia. Congreso de la República. (1978). Ley 61. Ley Orgánica del Desarrollo Urbano. Recuperado de http://www.minambiente.gov.co/documentos/ley_0061_151278.pdf.

Colombia. Presidencia de la República. (1986, 14 de mayo). Decreto 1333 de 1986. Código de Régimen Municipal. Diario oficial, CXXIII (37466), 17.

Corporación Autónoma Regional de Cundinamarca. (1998). Acuerdo 16/98. Determinantes ambientales para la determinación de planes de ordenamiento territorial municipal. Bogotá: CAR.

DANE. (2006). REDATAM_SP Censo Básico [base de datos]. Censo 2005. Recuperado de http://www.dane.gov.co/censo/

Departamento Administrativo de Planeación Nacional DNP. (2010). Glosario. Recuperado de http://www.dnp.gov.co/PortalWeb/-Glosario/tabid/802/Item/776/Default.aspx 
Departamento Administrativo de Planeación Nacional DNP. (2004). Documento Conpes 3305. Lineamientos para optimizar la política de desarrollo urbano. Bogotá: Consejo Nacional de Política Económica y social. DNP, Ministerio de Ambiente, Vivienda y Desarrollo Territorial.

Instituto Geográfico Agustín Codazzi. (2012ª). Estadísticas catastrales. Reporte estadístico municipio de Facatativá. Subdirección de Catastro. Documento no publicado, elaborado a solicitud del investigador. Bogotá.

Instituto Geográfico Agustín Codazzi. (2012b). Levantamiento de suelos en las áreas planas de 14 municipios de la Sabana de Bogotá. Mapa de capacidad de uso de las tierras en las áreas planas del municipio de Facatativá. Mapas a escala detallada y general. Bogotá: IGAC.

Instituto Geográfico Agustín Codazzi. (2009). Atlas de Cundinamarca. Bogotá: IGAC. 202 p.

Instituto Geográfico Agustín Codazzi. (1989). Proceso de urbanización en Colombia. Análisis geográfico, (15). Bogotá: IGAC. 258 pp.

Instituto Geográfico Agustín Codazzi. (1984). Estudio regional integrado del altiplano cundiboyacense. Bogotá: IGAP. 415 pp.

López del Trigal, L. \& Benito del Pozo, M. (1999). Geografía política. Madrid: Ediciones Cátedra. 304 pp.

Massiris, A. (2009). Desarrollo territorial sostenible en América Latina. En J. Farinós, J. Romero \& J. Salom. (Eds.) Cohesión e inteligencia territorial. Dinámicas y procesos para una mejor planificación y toma de decisiones. PUV 7. (pp. 121-138). Valencia: Universidad de Valencia.

Massiris, A. (2005). Fundamentos, conceptos y métodos del ordenamiento territorial. Tunja: Universidad Pedagógica y Tecnológica de Colombia UPTC. 122 pp.

Muller, P. (2002). Políticas públicas. J. F. Jolly \& C. Salazar (Trad). Bogotá: Universidad Externado de Colombia. 200 pp.

Muñoz, O. (2007, diciembre). Estudio de la dinámica de los factores del desarrollo local en el municipio de Facatativá (Cundinamarca). Revista OIDLES, 1 (2). Recuperado de http://www.eumed.net/rev/oidles/02/Munoz.htm

Ortega, J. (2000). Los horizontes de la geografía. Barcelona: Ariel.

Sánchez, J. 1(992). Geografía Política. Colección Espacios y Sociedad No. 23. Madrid: Síntesis. 222 pp. 
Shlomo, A., Parent, J., Civco, D. \& Blei, A. (2010). The persistent decline in urban densities: global and historical evidence of 'Sprawl. Cambridge, MA: Lincoln Institute of Land Policy. Recuperado de www.lincolninst.edu/pubs/dl/1834_1085_Angel\%20 Final \%201.pdf

Solá-Morales, M. (1997). Las formas de crecimiento urbano. Barcelona: Universidad Politécnica de Cataluña.

Thoenig, J-C. (2006). Política Pública. En Diccionario de políticas públicas. Traducción (2009). Bogotá: Universidad Externado de Colombia. pp. 334-340.

Troitiño, M. (2006). Ordenación del territorio y desarrollo territorial: la construcción de geografías del futuro. En M. E. Salina (comp.). Ordenamiento territorial: experiencias internacionales. Guadalajara: Secretaría del Medio Ambiente y Recursos Naturales (SEMARNAT), Instituto Nacional de Ecología (INE) Universidad de Guadalajara.

Recepción: 27 de septiembre de 2012

Evaluación: 15 de octubre de 2012

Aprobación: 29 de octubre de 2012 